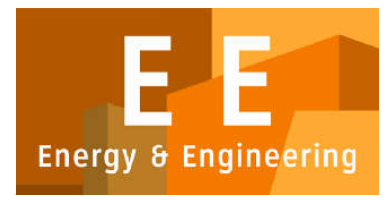

PAPER - OPEN ACCESS

\title{
Penerapan Kaizen dalam Rangka Meningkatkan Loyalitas Pelanggan di PT XYZ
}

\author{
Author $\quad$ : John Warisman Sinaga, dkk \\ DOI $\quad: 10.32734 /$ ee.v2i4.679 \\ Electronic ISSN $\quad: 2654-704 X$ \\ Print ISSN : :2654-704X
}

Volume 2 Issue 4 - 2019 TALENTA Conference Series: Energy \& Engineering (EE)

\section{(ㅇ) $(19$}

This work is licensed under a Creative Commons Attribution-NoDerivatives 4.0 International License.

Published under licence by TALENTA Publisher, Universitas Sumatera Utara 


\section{jibli \\ TALENTA Conference Series}

-
Available online at https://talentaconfseries.usu.ac.id

\title{
Penerapan Kaizen dalam Rangka Meningkatkan Loyalitas Pelanggan di PT XYZ
}

\author{
(Kaizen Implementation in the Framework of Increasing Customer Loyalty at PT XYZ)
}

\author{
John Warisman Sinaga ${ }^{1}$, Nazaruddin Matondang ${ }^{1}$, Sukaria Sinulingga ${ }^{1}$, Jeffrey Panama ${ }^{2}$ \\ ${ }^{1}$ Program Studi Magister Teknik Industri dan Doktor Ilmu Teknik Industri, Universitas Sumatera Utara \\ ${ }^{2}$ Departemen Teknik Industri, Universitas Sumatera Utara
}

E-mail: johnsinaga36@gmail.com; nazarmtd60@gmail.com; jeffreypanama.usu@gmail.com

\begin{abstract}
Abstrak
Kaizen digunakan untuk melakukan perbaikan secara terus menerus, menggunakan tahapan-tahapan kecil yang melibatkan manager dan seluruh pegawai dengan biaya dan resiko yang relatif akan lebih rendah. Bengkel PT. Trans Suzuki Sumatera Agung merupakan salah satu unit kegiatan untuk mendukung dan meningkatkan pelayanan pelanggan Suzuki. Indikator utama dalam pelayanan bengkel adalah kepuasan pelanggan. Berikut ini merupakan uraian dalam penerapan $5 \mathrm{~s}$ yang terdapat dalam konsep kaizen. Seiri, meminimalisir hal/benda tidak penting, seiton, menyusun peralatan serapi mungkin agar memberikan kemudahan dalam bekerja. Seiso, melakukan pembersihan terhadap mesin/peralatan yang telah digunakan. Seiketsu, menhaga, merawat dan mengikuti ketiga tahap sebelumnya. Shitsuke, memelihara dan meningkatkan disiplin individu pekerja. Hasil penerapan kaizen memberikan usulan kebijakan yang diterapkan oleh PT XYZ sehingga diharapkan dapat memberikan dampak peningkatan kepuasan pelanggan pada periode selanjutnya. Usulan kebijakan tersebut terkait dengan penambahan jumlah mekanik, melakukan perbaikan terhadap ruang tunggu pelanggan, pelaksanaan pelatihan bagi pekerja, pergantian komponen/peralatan yang rusak serta perbaikan terhadap kinerja booking service.
\end{abstract}

Kata kunci : Loyalitas Pelanggan; Kaizen; 5S

\begin{abstract}
Kaizen is used to make continuous improvements, using small steps that involve managers and all employees with relatively lower costs and risks. PT. Trans Suzuki Sumatera Agung is one of the activity units to support and improve Suzuki's customer service. The main indicator in service shop is customer satisfaction. The following is a description of the application of the 5 s contained in the kaizen concept. Seiri, minimize things / objects that are not important, seiton, arrange equipment as neat as possible to provide convenience in working. Seiso, clean the machinery / equipment that has been used. Seiketsu manned, cared for and followed the three previous stages. Shitsuke, maintains and improves individual worker discipline. The results of the application of kaizen provide policy proposals implemented by PT XYZ so it is expected to have an impact on increasing customer satisfaction in the next period. The proposed policy is related to increasing the number of mechanics, making improvements to the customer's waiting room, conducting training for workers, replacing damaged components / equipment as well as improving the booking service performance.
\end{abstract}

Keywords: Customer Loyalty; Kaizen; 5S

(C) 2019 The Authors. Published by TALENTA Publisher Universitas Sumatera Utara

Selection and peer-review under responsibility of Seminar Nasional Institut Supply Chain dan Logistik Indonesia

(ISLI) 2019

p-ISSN: 2654-7031, e-ISSN: 2654-704X, DOI: 10.32734/ee.v2i4.679 


\section{Pendahuluan}

Kaizen adalah peningkatan yang berkelanjutan, sistematis, bertahap dalam hal-hal yang dilakukan. Ini adalah upaya tanpa henti untuk menghilangkan kegiatan yang tidak perlu, penundaan, pemborosan dan variasi proses bisnis yang menambah biaya tanpa menambah nilai [1]. Kaizen menghasilkan peningkatan waktu, efisiensi, kualitas, produktivitas dan loyalitas pelanggan. Teknik kaize secara khusus dibedakan sebagai metode peningkatan kinerja terbaik di seluruh dunia, di dalam perusahaan karena biaya penerapannnya minimal. Saat ini lebih dari sebelumnya bahwa hubungan antara manager dan karyawan sangat penting dan teknik kaizen memiliki kontribusi besar pada penguatan hubungan ini karena prestasi perusahaan adalah hasil dari upaya campuran masing-masing karyawan. Metode-metode ini menyatukan semua karyawan perusahaan untuk memastikan peningkatan proses komunikasi dan penguatan rasa keanggotaan. Saat ini, mengingat fenomena global, kita dapat melihat bahwa di bidang industri mobil, produk dan layanan dapat dibandingkan satu sama lain, siklus hidup produk semakin berkurang sedangkan interval layanan semakin lama semakin panjang. Gambar 1 merupakan gambaran sistem kaizen.

Perkembangan dunia industri dewasa ini memberikan konsekuensi secara langsung terhadap persaingan di dunia bisnis. Di sisi lain, masyarakat sebagai konsumen memiliki sikap yang berflukstuasi dan semakin kritis terhadap produk dan jasa yang dihasilkan oleh produsen [2]. Schnaars dalam Santoso menjelaskan bahwa setiap produsen pada dasarnya memiliki tujuan untuk memberikan kepuasan terhadap pelanggan [3]. Hal ini disebabkan karena komitmen terhadap kualitas yang dihasilkan menjadi salah satu faktor utama keberhasilan suatu bisnis, terutama yang bergerak dibidang jasa. PT. XYZ merupakan salah satu unit kegiatan bengkel yang diteliti untuk mendukung dan meningkatkan pelayanan pelanggan PT. XYZ. Indikator utama dalam pelayanan bengkel ini adalah kepuasan pelanggan.

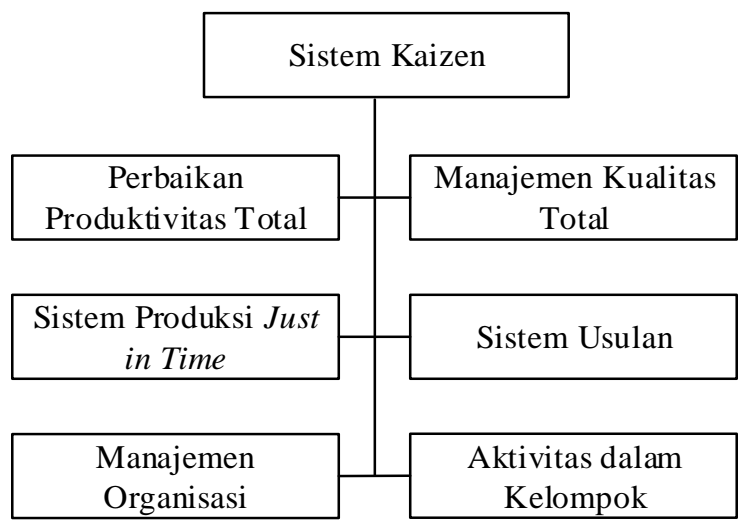

Gambar 1. Sistem Kaizen

Survey awal yang telah dilakukan di bengkel mobil Suzuki PT. Trans Sumatera Agung, menunjukkan bahwa perusahaan ini sudah memberikan perhatian yang cukup baik terhadap loyalitas pelanggan. Hal ini dibuktikan dengan adanya beberapan penawaran yang berbeda dengan bengkel sejenis lainnya. Perbedaan tersebut diantaranya adalah delivery time yang siap bekerja saat hari libur kerja. Selain itu, bengkel mobil Suzuki juga selalu memperhatikan setiap keluhan yang diberikan pelanggan terkait dengan kesalahan dalam perbaikan dan tentunya akan dilakukan penanganan secepat mungkin untuk menjaga kepuasan pelanggan. 


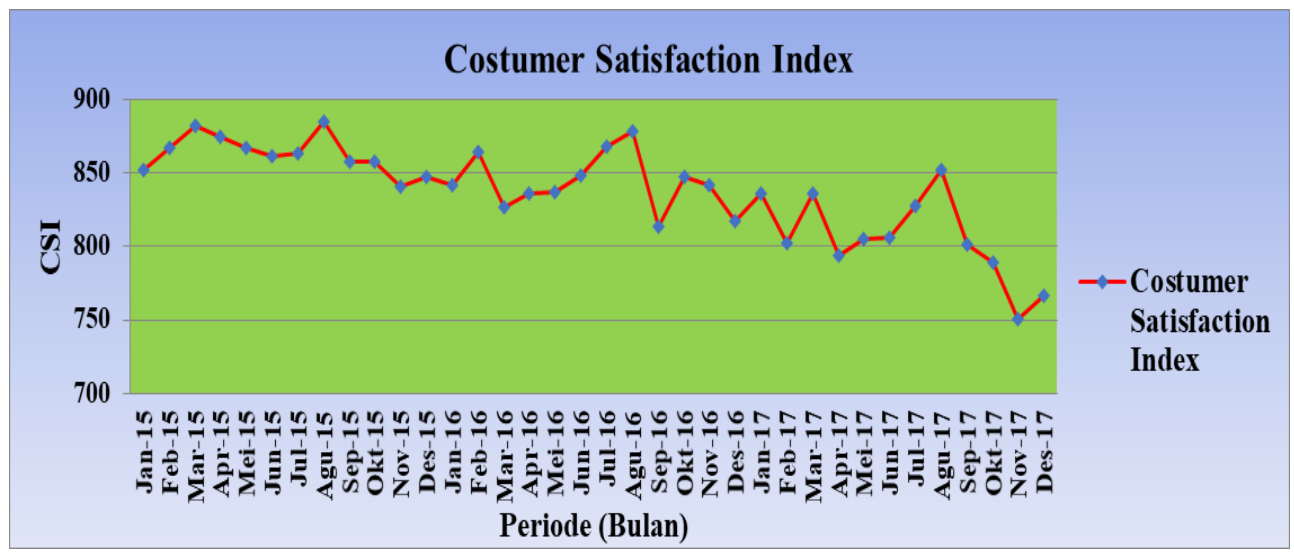

Gambar 2. Penurunan CSI dan Service Retention

Gambar 2 merupakan data historis perusahaan terkait dengan Unit entry, revenue, service retention dan costumer satisfaction index (CSI) periode 2015 sampai dengan 2017. Dari data tersebut dapat dilihat bahwa revenue dan unit entry mengalami peningkatan dari tahun 2015 dengan tahun sesudahnya. Jika dilihat dari costumer satisfaction index (CSI), terjadi penurunan dari tahun 2015 dengan periode sesudahnya. Adanya persentase penurunan index CSI diatas menandakan bahwa pelanggan masih kurang puas terhadap pelayanan yang diberikan perusahaan selama ini. Hal ini jika tidak dilakukan perbaikan yang relevan, akan berdampak buruk bagi loyalitas pelanggan PT. XYZ.

\section{Metodologi Penelitian}

Permasalahan yang dialami oleh perusahaan adalah terjadinya penurunan terhadap service retention dan customer satisfaction index (CSI) periode 2015 sampai dengan 2017. Selanjutnya penurunan tersebut disebabkan oleh adanya keluhan pelanggan terhadap beberapa atribut CSI dan memiliki persentase ketidak puasan diatas $10 \%$. Atribut CSI yang dimaksud adalah ketelitian service advisor, kenyamanan ruang tunggu, kebersihan dealer, kemudahan keluar masuk area dealer, penetapan biaya servis, jangka waktu pengambilan kendaraan, total waktu servis dan ketelitian teknisi. [4]

Jenis penelitian bersifat korelasional. Penelitian korelasional adalah penelitian jenis survey yang memiliki tujuan untuk melihat keeratan hubungan dari variabel bebas dengan variabel terikat penelitian. Selanjutnya, populasi yang digunakan dalam penelitian ini adalah semua pelanggan PT XYZ yang melakukan perbaikan pada periode Maret 2018 sampai Juni 2018 dengan teknik pengambilan sampel menggunakan non probability sampling, yaitu incidental sampling. Sumber data penelitian yang digunakan terdiri dari data primer dan data sekunder [5]:

\section{Data Primer}

Data primer didapatkan secara langsung dari responden penelitian, yang terdiri dari:

a. Identitas responden seperti usia, jenis kelamin, status pekerjaan, tingkat pendidikan serta frekuensi kedatangan ke bengkel.

b. Tanggapan dan penilaian responden yang dikumpulkan melalui pengisian kuesioner.

2. Data Sekunder

Data sekunder merupakan data yang diperoleh dari studi kasus pustaka dan sumber lain yang menunjang jalannya penelitian ini.

Variabel dependent adalah loyalitas pelanggan dengan kepuasan pelanggan sebagai variabel moderasi [6]. Kepuasan pelanggan mengacu kepada keadaan dimana kelompok pelanggan merasa senang dengan tingkat layanan yang mereka terima, karena memenuhi atau melampaui tingkat layanan yang mereka harapkan. Selanjutnya, variabel bebas berupa dimensi kualitas jasa pelayanan yaitu:

1. Tangible, merupakan fasilitas fisik bengkel, peralatan/mesin, serta penampilan para pegawai bengkel.

2. Reliabilty, merupakan kemampuan dalam memberikan pelayanan yang bersifat akurat dan handal. 
3. Responsiveness, mengacu kepada kesediaan para pegawai/petugas untuk menanggapi dan memberikan pelayanan yang cepat kepada pelanggan.

4. Assurance, merupakan jaminan pengetahuan dan kemampuan pihak bengkel untuk meyakinkan dan memberikan kepercayaan yang baik kepada pelanggan.

5. Emphaty, mengacu kepada perhatian dan kepedulian individual perusahaan terhadap pelanggannya.

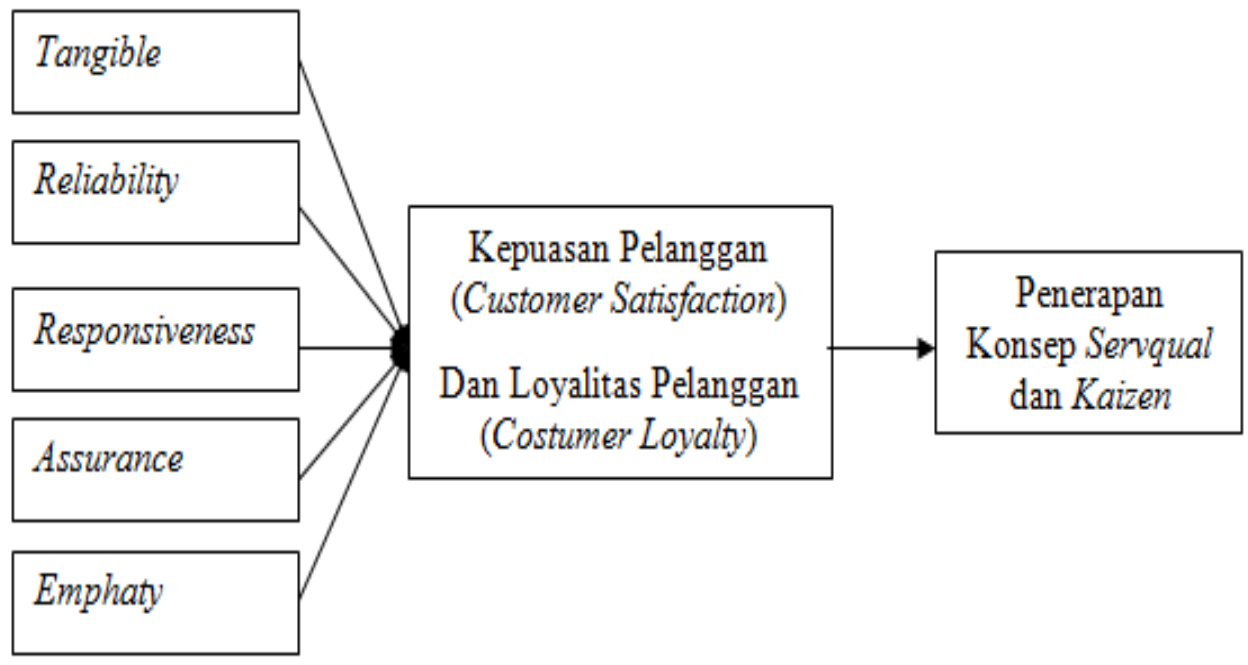

Gambar 3. Kerangka Konseptual

Kaizen digunakan sebagai strategi perbaikan, strategi bagaimana melakukan sesuatu dengan lebih baik, sementara semua aktivitas pada akhirnya harus mengarah kepada peningkatan kepuasan dan loyalitas pelanggan. Kaizen berfokus kepada perbaikan kecil, bertahap dan sering sepanjang periode waktu dengan investasi minimum sumber daya keuangan. Pendekatan peningkatan berkelanjutan mengarah kepada efek kecil tetapi sering melalui perubahan kecil dalam sistem yang ada. kaizen juga digambarkan sebagai filosofi keseluruhan yang berjuang untuk kesempurnaan setiap hari. Ini adalah proses untuk memastikan peningkatan pertumbuhan, betapapun kecilnya mereka, dan mencapai "condong" dalam bentuk penghapusan semua kerugian yang menghasilkan biaya tanpa menambahkan nilai apapun. Kaizen mengajarkan individu keterampilan kerja yang efisien untuk aktivitas sederhana, memecahkan permasalahan, membuat dokumentasi, memperbaiki proses, pengumpulan dan analisa data serta selalu memperbaiki hubungan baik dalam tim kerja dengan rekan lainnya. Penerapannya di tempat kerja berarti mencari dan menghilangkan pemborosan secara permanen dan peningkatan berkelanjutan dalam produks, kualitas dan fleksibilitas, yang melibatkan semua orang, manager dan juga karyawan biasa. Wisner dan Stanlay mendefinisikan perbaikan berkelanjutan sebagai cara berpikir berorientasi proses dan pendekatan manajemen proaktif untuk pemecahan masalah dalam suatu organisasi.

Daripada menunggu sampai terjadi masalah atau persaingan mengancam bisnis mereka dan kemudian bereaksi atau "memadamkan api", perusahaan harus diorganisir di semua tingkatan untuk melakukan peningkatan secara terus menerus, selalu dengan mempertimbangkan pelanggan eksternal. Titik awal dari suatu peningkatan adalah kemampuan untuk melihat kebutuhan akan suatu peningkatan, yaitu kemampuan untuk melihat dan menyadari masalah dan tempat-tempat yang terbuang. Itulah sebabnya kepuasan adalah musuh utama kaizen. Segera setelah masalah diidentifikasi, perlu dipecahkan. Pada saat yang sama, peran utama dimainkan oleh karyawan. Ketika manager memberikan karyawan alat, dukungan, dan dorongan untuk membantu mereka mengidentifikasi masalah, mengevaluasi alternatif, dan membuat keputusan yang tepat, produk dan proses akan meningkat. Untuk membuat level yang dicapai bertahan, setiap peningkatan harus distandarisasi. Ketika kaizen diterapkan di tempat kerja, semua orang di perusahaan harus berjuang, bersama dengan yang lain, untuk menerapkan tiga aturan; peningkatan, penghapusan pemborosan dan standarisasi. 


\section{Hasil dan Pembahasan}

Kaizen digunakan sebagai konsep perbaikan berkelanjutan secara terus menerus, melaui langkah atau tahap yang sederhana melibatkan manager maupun karyawan dengan biaya dan resiko rendah. Gambar 4. merupakan jenis-jenis Kaizen.

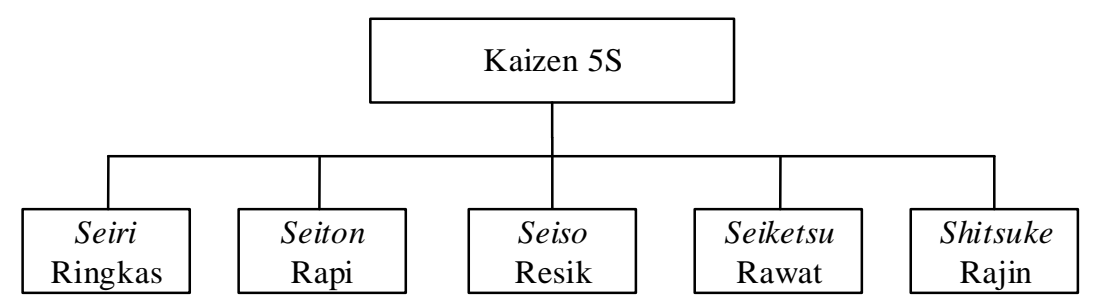

Gambar 4. Kaizen 5S

Dibawah ini merupakan uraian penerapan 5S di PT. XYZ, yaitu:

1. SEIRI: Meminimalisir hal/benda yang dinilai tidak penting dan meletakkan pada tempat seharusnya. Hasil pengamatan menunjukkan bahwa perlu dilakukan untuk menempatkan barang-barang yang tidak diperlukan di bengkel resmi Suzuki PT Trans Sumatra Agung seperti peralatan bengkel yang tidak digunakan lagi, ATK, dan barang lainnya.

2. SEITON : Melakukan penyusunan peralatan atau segala sesuatu yang terdapat di daerah kerja dengan tujuan mempermudah aktivitas pekerjaan. Hasil pengamatan menunjukkan bahwa area kerja yang perlu dirapikan kembali adalah meja resepsionis, ruang tunggu dan bagian parkir kendaraan. Sebaiknya ATK di meja resepsionis disusun rapi dan ditempatkan pada tempat yang semestinya agar tidak mengakibatkan penilaian yang kurang baik dari pelanggan.

3. SEISO : kegiatan membersihkan peralatan kerja setelah selesai digunakan. Aktivitas ini diperlukan khususnya bagi karyawan yang bertugas untuk memperbaiki kendaraan pelanggan secara langsung. Sebaiknya peralatan yang telah selesai digunakan tersebut dibersihkan kembali. Hal ini bertujuan untuk menjaga performa peralatan agar tetap baik dalam jangka waktu yang cukup lama.

4. SEIKETSU: merawat, menjaga serta mematuhi setiap tahapan sebelumnya secara berkelanjutan dan konsisten. Implementasi dari tahapan ini seperti kegiatan inspeksi (mengecek ulang) dan melakukan perawatan secara preventif ataupun korektif terhadap mesin produksi yang digunakan.

5. SHITSUKE : merupakan kegiatan yang berfokus untuk meningkatkan dan memperbaiki kedisiplinan diri pekerja untuk terus menerus mengaplikasikan penerapan kaizen di lingkungan kerja. Pekerja harus selalu diberikan motivasi, dorongan serta kesadaran agar mau melakukan perbaikan diri terhadap kesalahan-kesalahan yang mungkin berpotensi untuk menurunkan produktivitas perusahaan.

\section{Kesimpulan}

Kesimpulan yang dapat ditarik sesuai dengan pembahasan sebelumnya adalah perusahaan perlu menerapkan dan mengawasi penerapan konsep kaizen di bengkel untuk memberikan kepuasan yang lebih baik kepada pelanggan. Usulan perbaikan yang diberikan melalui penerapan kaizen ini adalah penambahan jumlah mekanik, melakukan perbaikan terhadap ruang tunggu pelanggan, pelaksanaan pelatihan bagi pekerja, pergantian komponen/peralatan yang rusak serta perbaikan terhadap kinerja booking service.

\section{Daftar Pustaka}

[1] Yekson Soll, Dkk. (2017). "Perbaikan Kualitas Pelayanan Jasa dengan Metode Servqual Dan Kaizen.” Surabaya: Institut Teknologi Adhi Tama. hlm 55-58. 
[2] Sinaga, Partua, P, H. (2011). “Analisis Pengaruh Kualitas Pelayanan, Kepuasan Pelanggan, dan Lokasi Terhadap Loyalitas Pelanggan Warnet Chamber" Semarang, Universitas Diponegoro. hlm 68-73.

[3] Singh, M.R.P. (2012). "Concept and Nature of Service.” India: Marketing of Service. p. 132-138.

[4] Sharmin, Wadud. (2012). "Customer Satisfaction in Business." Finland: Laurea Prime. p. 32.

[5] Sinulingga, Sukaria. (2011). "Metode Penelitian. Edisi Pertama." Medan: USU Press. hlm 48-49.

[6] Kotler, Philip dan Kevin Lane Keller. (2007). "Manajemen Pemasaran. Edisi Kedua Belas.” Jakarta: Indeks. hlm 24-26. 